\title{
Multi-temporal analysis of land use and vegetation cover in São Francisco do Sul and Itapoá, Santa Catarina State - Brazil: implications to groundwater contamination
}

\author{
A.C.S.J.V. Ferreira ${ }^{1, *}$, L.S. Osako. ${ }^{1}$
}

${ }^{1}$ Department of Geology, Federal University of Santa Catarina, Brazil - ana.jardim@grad.ufsc.br, liliana.osako@ufsc.br

KEY WORDS: Remote sensing, land use, land cover, GEOBIA, image classification

\begin{abstract}
:
By means of the multitemporal approach, we analyze the changes in land use and vegetation cover in the São Francisco do Sul and Itapoá municipalities, located in the northern coast of the State of Santa Catarina, Brazil. LANDSAT satellite images from 1991 to 2019 were analyzed and classified into four classes of soil use and occupation (vegetated area, bare soil, urbanized area, and water body) by the GEOBIA method. Weighted sum analysis was applied to the 'urbanized area' class and the data available on geologic units, so as to identify areas vulnerable to groundwater contamination. The vegetated areas of São Francisco do Sul and Itapoá have diminished along the 2000 's, but recovery measures, such as reforesting and restraint of soil exposure, have been adopted, with $89.61 \%$ success. The urban zone has increased $3.36 \%$ in the last 28 years. The achieved overall accuracy for the classification was of $79.33 \%$ and the Kappa coefficient was 0.69 . The analysis of groundwater vulnerability to contamination helped identify regions more susceptible to pollution, which coincide almost entirely with those where urbanization was more intense in areas where unconsolidated sediments predominate.
\end{abstract}

\section{INTRODUCTION}

Human occupation has been historically more intense and concentrated in regions near the coast than inland. In the past decades, new technologies, population growth and accelerating changes in coastal environments have made it impossible not to think about how human activities have caused impacts to geological and ecological systems and to adopt measures, taking into account environmental sustainability for human life itself. Coastal systems are considered to be very sensitive to changes, and therefore non-supervised urbanization of these areas can lead to disasters concerning geological aspects - destabilization of the dynamic system - and ecological aspects - modification of the environment and consequently the way of living of species in those habitats, and also humans, whose well-being is highly dependent upon the balance of a variety of systems.

The main goal of this study is to analyse the evolution of land use and vegetation cover in the São Francisco do Sul and Itapoá municipalities, located in the northern coast of the State of Santa Catarina - Brazil (figure 1), using a multi-temporal approach (satellite images from 1991 to 2019). Both municipalities host two important ports, the Itapoá port and TESC (Santa Catarina port terminal), installed in the São Francisco do Sul Island. The ports evolved as the region evolved and this evolution is strongly related to the regional economy, which led to an increase in population and exploitation of natural resources, so as to support economic goals and subsistence needs. Another goal of this research is to identify areas with higher groundwater vulnerability to contamination, taking into account the geological aspects of these areas. The susceptibility of the geological material to infiltration was taken into account, as well as the classes/sectors that contribute most to contamination.

\section{STUDY AREA}

The São Francisco do Sul Island partly covered by the Atlantic Rainforest biome, which is mainly an Ombrophilous forest (IBGE, 2004). Grasses and mangroves typical of coastal environments are also present, but are better identified in largescale images (Souza, 1999).

\footnotetext{
* Corresponding author
}

The annual precipitation range is 1050 and $1750 \mathrm{~mm}$, and is well distributed along the year, even considering rainfall concentration in the summer (Souza, 1999).

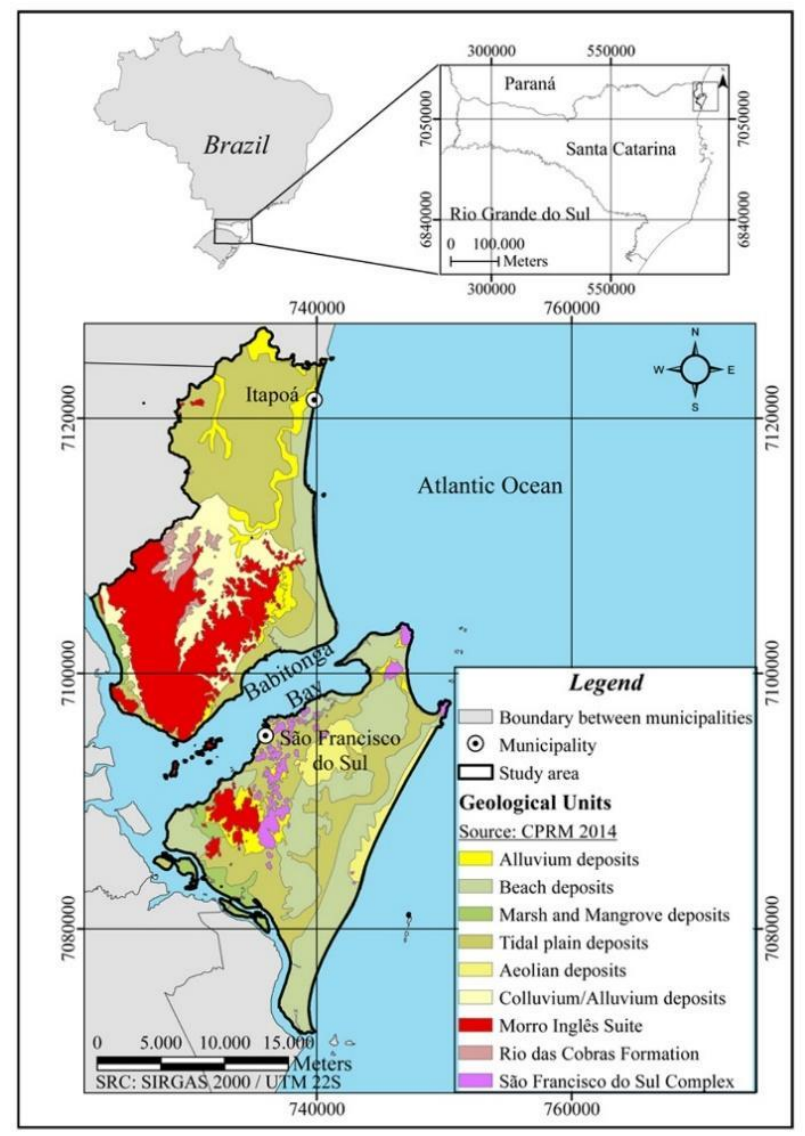

Figure 1. Simplified geological map of the study area, highlighting the São Francisco do Sul and Itapoá municipalities (Modified after Wilder et al., 2014).

Geomorphologically, the area is characterized by Highlands and Lowlands (Horn Filho, 1997). The Highlands are the highest 
elevations of the coastal plain and have been dissected by fluvial erosion and structural controls. The geological context is represented by orthogneisses and paragneisses of the Archean Santa Catarina Granulitic Complex; gneiss and quartz monzodiorite and trondhjemites of the Paleoproterozoic São Francisco do Sul Complex; supracrustal rocks of the Neoproterozoic Rio das Cobras Formation, and Neoproterozoic leucocratic granitic rocks of the Morro Inglês Suite and Rio do Poço Granite (Wildner et al., 2014).

Quaternary colluvium and alluvium fan deposits cover the Highlands scarps (Horn Filho and Diehl, 2006). The Lowlands that correspond to the coastal plain are mainly composed of smooth, slightly wavy or inclined surfaces that were formed by the accumulation of fluvial, marine, fluvio-marine, lacustrine, colluvium or aeolian sediments. Horn Filho (1997) highlights the presence of small bays and embayed beaches that were formed by the lowering of the continental topography, besides terraces, dunes, peninsulas, bays, tide plains, lagoons, cliffs and beaches.

\section{MATERIALS AND METHODS}

Figure 2 presents a flowchart of the materials and methods applied in this study.

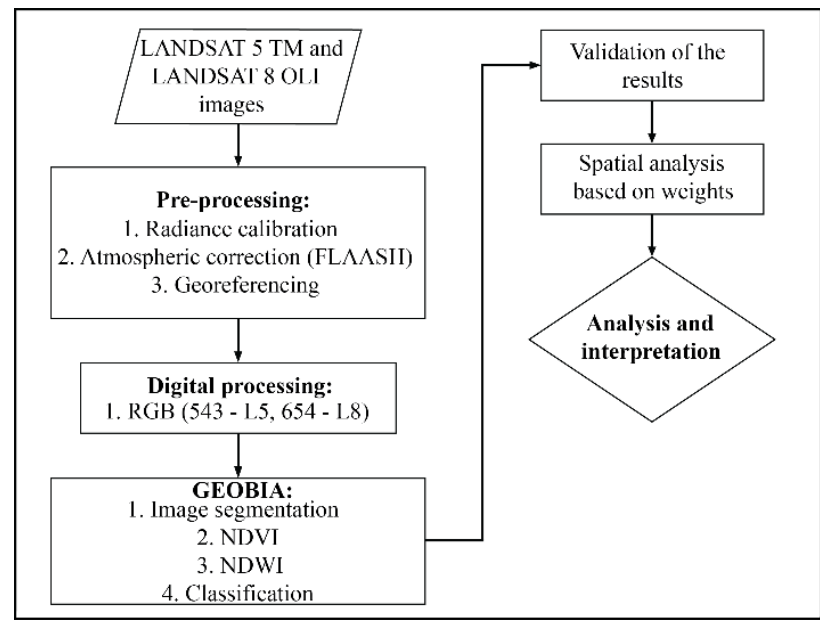

Figure 2. Flowchart of the materials used and methods applied in this study.

Three LANDSAT 5 TM multispectral images obtained in 1991 , 2000 and 2010 (L5), and a LANDSAT 8 OLI image from 2019 (L8) were acquired from the National Institute for Space Research of the Brazil (Instituto Nacional de Pesquisas Espaciais - INPE). Spatial resolution of all images is $30 \mathrm{~m}$.

The ENVI software was used to process the satellite images. Pre-processing was initially applied in order to enhance the visual quality of the images by removing or correcting errors and distortions caused by instrumental failure or atmospheric interference (Meneses and Almeida, 2012). This step consisted specially of radiance calibration and atmospheric correction via the FLAASH method.

The image classification method adopted in this study was the Geographic Object-Based Image Analysis (GEOBIA). The basis of the object-based classification is explained in Blaschke et al., (2014): "pixels do not come isolated but are knitted into an image full of spatial patterns. These patterns create objects, defined as 'meaningful' entities or scene components that are distinguishable in an image".
The indexed images and RBG compositions (543 - L5, $654-$ L8) were used during image classification via the e-Cognition software. The images were segmented by the multiresolution segmentation method. The scales applied on the segmentation of L5 and L8 were 30 and 20, respectively, while each band had the same weight $-1-$ and the segments form and compacity were value as 0.2 to every year.

After segmentation, rules were created (Table 1) in order to classify the segments into four different classes: vegetated area, bare soil and urban occupation. The creation of rules took into consideration the electromagnetic spectrum ranges in which all class information is enhanced and, therefore, they can be properly identified. Indexing equations and individual bands were used in this process, as follows:

Normalized Difference Vegetation Index (Jensen, 2004):

$$
N D V I=\frac{(N I R-R e d)}{(N I R+R e d)}
$$

Where NIR corresponds to near infrared and RED, to the red range on the visible.

The first classified segments were those that represented vegetated areas. The segments were identified mainly by the NDVI values and the inferior threshold was determined interactively - applying field knowledge of the region. Afterwards, all the remaining area was interpreted as nonvegetated area and from this larger class other attributes were interpreted. The water bodies (rivers and lakes) were individualized by de NDWI. The threshold between bare soil and urban areas also used the NDVI. As urban regions are those with smaller amount of vegetation, the smallest spectral response from NDVI associate to field knowledge was used to determine the range.

\begin{tabular}{|c|c|c|c|c|}
\hline & $\begin{array}{c}\text { L-5 } 1991 \\
\text { May }\end{array}$ & $\begin{array}{c}\text { L-5 } 2000 \\
\text { May }\end{array}$ & $\begin{array}{l}\text { L-5 } 2010 \\
\text { February }\end{array}$ & $\begin{array}{l}\text { L-8 } 2019 \\
\text { January }\end{array}$ \\
\hline 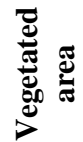 & $\begin{array}{c}\mathrm{NDVI} \geq \\
0.81\end{array}$ & $\begin{array}{c}\text { NDVI } \geq \\
0.76\end{array}$ & $\begin{array}{c}\mathrm{NDVI} \geq \\
0.65\end{array}$ & $\begin{array}{c}\text { NDVI } \geq \\
0.61\end{array}$ \\
\hline
\end{tabular}

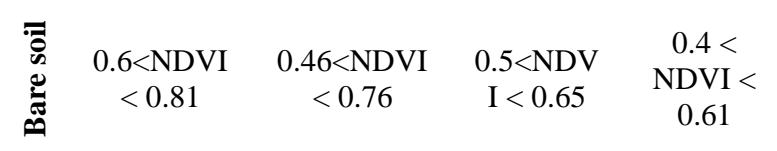

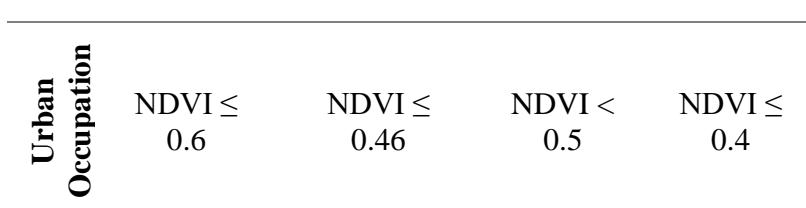

Table 1. Image classification rules for years 1991, 2000, 2010, and 2019.

The classification was checked in the field, in order to confirm and enhance the accuracy of the identified classes during image processing. The results were then analysed statistically, quantifying the area and evolution of each class during the years. Aiming at a better way to assess the differences in urban evolution, the study area was divided into sectors. Sectorization took into account the identified urbanization foci and the boundaries between the municipalities. 
The last step of this study was data analysis, interpretation, and understanding of how urban advance has caused impacts to the environment and contributed to groundwater contamination. According to Zhang et al. (2013), both aquifer and groundwater are highly "susceptible to contamination from land use and anthropogenic influence" and thus in need of risk assessment in order to protect the resource. The risk of contamination is defined as the intersection between natural vulnerability of the aquifer system and the danger of contamination (Rubim, 2019). The geological characteristics have influence on vulnerability and therefore represent risk. Most of the study area, i.e., both the island and the opposite continental region, occupies coastal plains, which concentrate unconsolidated Quaternary sediments that have been deposited during sea level rises and falls during the last million years.

Table 2 lists the susceptibility parameters adopted in this study. The geological units' parameters were defined taking into account sediment composition and studies of porosity and permeability presented by Morris and Johnson (1967), Kamann et al. (2007), Urumović and Sr (2016). The alluvium and colluvium-alluvium deposits, composed predominantly of badly sorted sand and gravel were considered more susceptible to infiltration because, even though there is a fraction of subordinately of fine particles, this fraction is not enough to fill the pore spaces between the sand grains, which would dimmish the porosity (Kamann et al., 2007). On the other hand, deposits composed mostly of fine-grained sediments (clay and silt), such as marshes, mangroves, and tidal plains have lesser effective porosity, as shown by Urumović and $\mathrm{Sr}$ (2016), and therefore, were considered less susceptible to infiltration. Beach and aeolian deposits are composed of sand, and according to the research of Morris and Johnson (1967) were considered of medium to high risk.

\begin{tabular}{|c|c|c|c|}
\hline \multicolumn{2}{|l|}{ Geological unit } & \multicolumn{2}{|c|}{ Land use } \\
\hline Alluvium deposits & 1 & $\begin{array}{c}\text { Urban } \\
\text { Occupation }\end{array}$ & 1 \\
\hline $\begin{array}{c}\text { Colluvium/Alluvium } \\
\text { deposits }\end{array}$ & 1 & Bare Soil & 0.8 \\
\hline Aeolian deposits & 0.9 & Vegetation & 0.1 \\
\hline Beach deposits & 0.8 & & \\
\hline $\begin{array}{l}\text { Marsh and mangrove } \\
\text { deposits }\end{array}$ & 0.5 & & \\
\hline Tidal plain deposits & 0.5 & & \\
\hline Basement rocks & 0 & & \\
\hline
\end{tabular}

Table 2. Weights attributed to susceptibility to groundwater contamination. The values were based on the lithological aspects of the geological units and the presence of contaminants in the regions of each class.

Weights were attributed to each class, considering the concentration of pollutants present in each region. The vegetated regions have a high rate of groundwater recharge, especially on agricultural areas where irrigation increases the water supply (Scanlon et al., 2005). Hence, this class was considered less vulnerable to contamination but still representing a risk due to the presence of pollutants - fertilizers and pesticides (Wang, 1989). Bare soil areas are more hazardous because of the combination of presence of pesticides in planted areas nearby and lack of protection provided by plant cover (Kumar et al., 2019). The greatest danger is found in urban zones due to the complete removal of the plant cover with impermeable materials and increased the runoff with higher concentrations of pollutants and contaminants (heavy metals, hydrocarbons, oils, pesticides and pathogens) (Wang, 1989). In addition, this area also has the presence of septic tanks and sewage. The influence of water bodies was not considered in this paper.

\section{RESULTS}

Table 3 and Figure 3 show the result of the statistical analysis of the evolution of soil use and occupation along 1991, 2000, 2010, and 2019.

\begin{tabular}{ccccc}
\hline Class/Year & $\begin{array}{c}\text { May } \\
\mathbf{1 9 9 1}\end{array}$ & $\begin{array}{c}\text { May } \\
\mathbf{2 0 0 0}\end{array}$ & $\begin{array}{c}\text { February } \\
\mathbf{2 0 1 0}\end{array}$ & $\begin{array}{c}\text { January } \\
\mathbf{2 0 1 9}\end{array}$ \\
\hline $\begin{array}{c}\text { Vegetated } \\
\text { area }\end{array}$ & 88.56 & 85.71 & 89.49 & 89.61 \\
\hline Bare Soil & 7.00 & 9.89 & 4.34 & 2.71 \\
\hline $\begin{array}{c}\text { Urban } \\
\text { occupation }\end{array}$ & 3.3 & 3.56 & 4.81 & 6.66
\end{tabular}

Table 3. Quantification of the areas (\%) represented by each class for the years of 1991, 2000, 2010, and 2019.

Between 1991 and 2000 there was a $2.85 \%$ reduction of vegetated area, concomitant with a $2.89 \%$ increase of bare soil. In the following years, the vegetated area was recovered, reaching $89.61 \%$ of the total area in 2019. After the peak of 2000 , the percentage in area of bare soil has reduced, representing only $2.71 \%$ of the total area in 2019 . Regarding the class 'urbanized area', a continuous growing has been observed along the years, from $3.3 \%$ to $6.66 \%$ of the total area.

\section{Classes variations between 1991 and 2019}

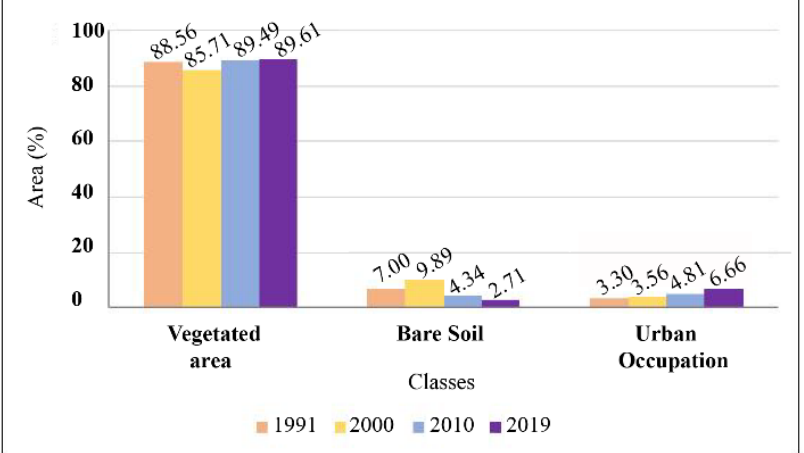

Figure 3. Graph showing the variation in area (\%) of each class along the years in the São Francisco do Sul and Itapoá municipalities.

\subsection{Urban Occupation}

Figure 4 illustrates the evolution of the urban development along the years. Sectors $1,2,5$ and 9 presented the greatest urban development.

Sector 1 encompasses the Ubatuba, Enseada, Forte and Capri beaches. It is a region where urban development has been intense since 1991. Field work revealed that this urbanization is mainly related to the residential and commercial real estate advance. Development related to the installation of TESC is expressed by areas deforested for port storage.

Sector 2 includes the central São Francisco do Sul neighborhood and TESC. Urban development has been intense in this sector, not only as a result of commercial and residential real estate advance, but also of the evolution of the port and its facilities, with ample areas used for storage and logistics. A 
limiting factor for a greater urban expansion in this sector is the presence of headlands constituted by basement rocks.

Sector 3 is the most vegetated and preserved region of the study area, thanks to Acaraí Statal Park, which is a conservation unit (created by Decree 3.517, dated September 23rd, 2005). It encompasses almost the totality of the Grande beach, where no urbanization or deforestation foci are observed, only native sandbank vegetation. Therefore, in Sector 6 - which includes the whole continental area of the São Francisco do Sul municipality - vegetation has been preserved and urbanization has been restricted to the coast, following the Babitonga Bay. Sandbank and mangrove vegetation has been preserved along the beaches of this sector (Figure 5).

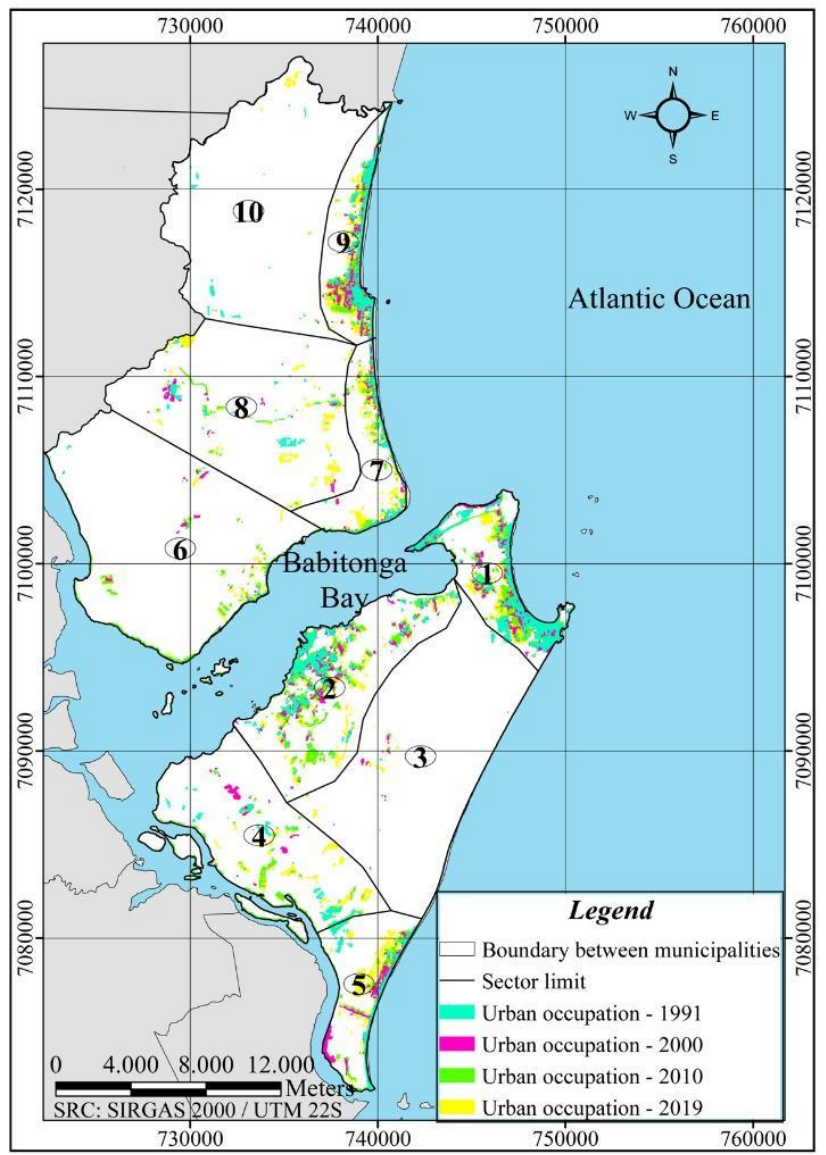

Figure 4. Map showing the urban zone evolution between 1991 and 2019.

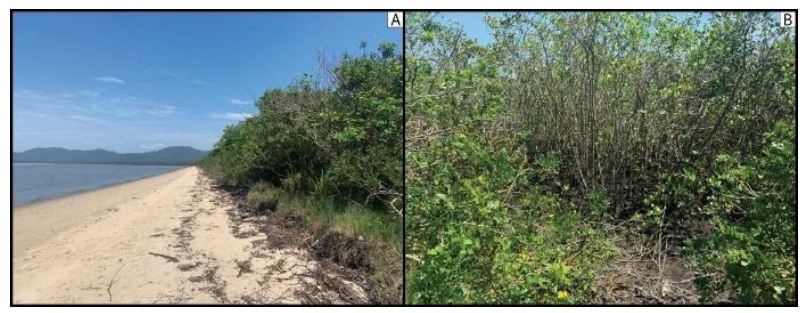

Figure 5. Characterization of the sandbank and mangrove vegetation. (Source: the authors).

Urban development is less intense and less focused on residential real estate development in sector 4. Sand mining, fish farming, and agriculture are on-going economic activities in this sector. Areas covered by native vegetation (figure 6) and some reforesting foci are observed.

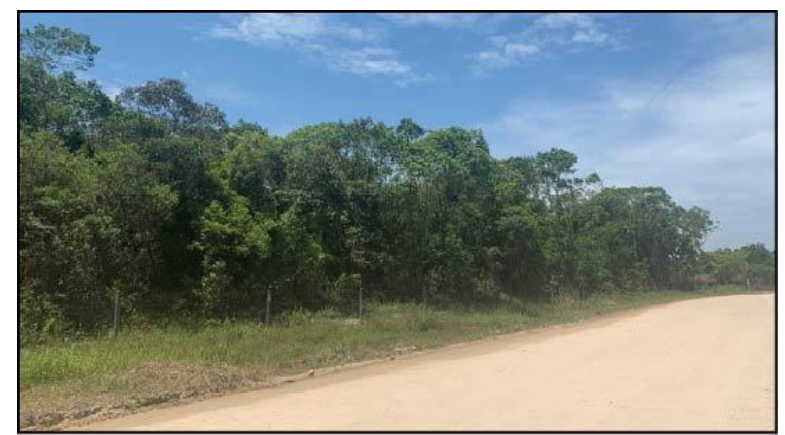

Figure 6. Characterization of the Atlantic Rainforest in sector 4 of the São Francisco do Sul Island. (Source: the authors).

In sector 5 urban development starts close to the Grande beach and advances inland. Residential real estate is dominant there.

Urbanization has advanced along the years in sector 7, mostly as a result from the installation of the Itapoá Port (figures 7 and 8 ), located south of the sector. Thus, urbanization of sector 7 is similar to that of sector 2, characterized by residential, commercial and port activities. Urbanization is also strong in Sector 9, which is mainly related to residential and commercial development.

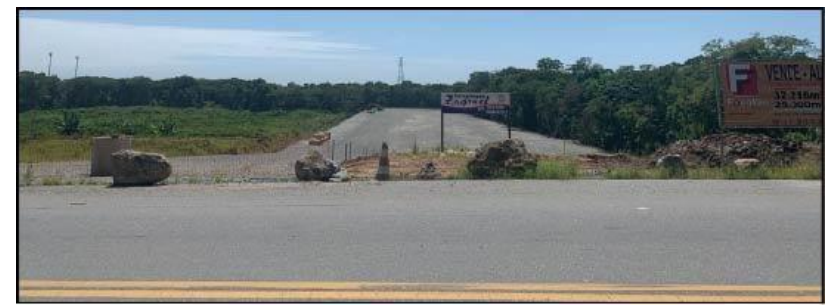

Figure 7. Deforested area in sector 7, used for port storage. (Source: the authors).

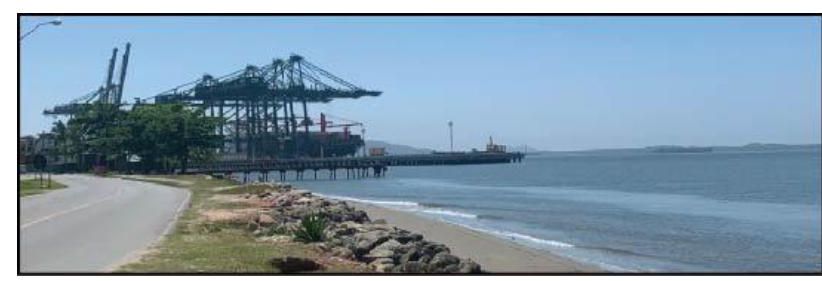

Figure 8. The Itapoá Port. (Source: the authors).

Sectors 8 and 10 are the least urbanized. The urban foci identified in these sectors are mainly related to agriculture, with a few areas for port storage and no residential or commercial development. Reforesting was also observed in these sectors (figure 9).

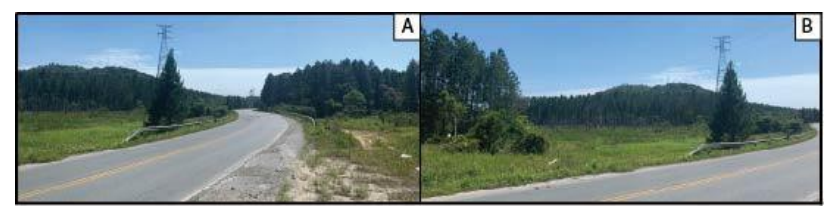

Figure 9. Characterization of grass vegetation in contact with reforested area in sector 8. (Source: the authors).

\subsection{Results accuracy}

The Kappa coefficient was calculated in order to identify the accuracy and precision of the classification (Foody, 1992). The 
confusion matrix and the calculated Kappa coefficient are shown in table 4

\begin{tabular}{|c|c|c|c|c|c|}
\hline \multicolumn{6}{|c|}{ Reference } \\
\hline \multirow{4}{*}{ 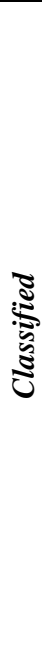 } & & $\begin{array}{c}\text { Vegetated } \\
\text { Area } \\
\end{array}$ & $\begin{array}{c}\text { Bare } \\
\text { Soil } \\
\end{array}$ & $\begin{array}{c}\text { Urban } \\
\text { Occupation }\end{array}$ & Total \\
\hline & 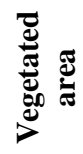 & 41 & 1 & 8 & 50 \\
\hline & 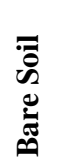 & 1 & 35 & 14 & 50 \\
\hline & 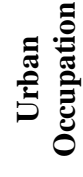 & 1 & 6 & 43 & 50 \\
\hline \multicolumn{2}{|c|}{ Total } & 43 & 42 & 65 & 150 \\
\hline
\end{tabular}

\begin{tabular}{|c|c|}
\hline Overall accuracy & $79.33 \%$ \\
\hline Kappa Coefficient & $\mathbf{0 . 6 9}$ \\
\hline
\end{tabular}

Table 4. Confusion matrix and Kappa coefficient.

This Kappa coefficient result was 0.69 and the achieved overall accuracy was of $79.33 \%$. This result is classified by Landis and Koch (1977) measurement scale as substantial and by Monserud and Leemans (1992)'s scale as good.

\subsection{Analysis of groundwater vulnerability to contamination}

From the definition of parameters (weights) of susceptibility to infiltration, the analysis that resulted in the map presented in Figure 10 was performed. It resulted from the intersection soil use and occupation data and geological characteristics. Regions at high risk of contamination are identified in red, that is, regions with high urban pollution potential and high susceptibility to infiltration.

The sectors that represent a high risk of aquifer contamination are 1, 5, 7, and 9. These regions have grown along the coastal plain, where unconsolidated sediments predominate. Beach, aeolian and alluvium deposits present the highest susceptibility to infiltration, as they are mainly composed of poorly sorted, sand-gravel sediments. Despite the accelerated urban evolution along the years in sector 2, groundwater vulnerability to contamination is reduced in this region thanks to the outcropping basement rocks.

The graph presented in figure 11 shows how the susceptibility differs among the sectors. Sectors 1 and 9 are the ones with higher risk of groundwater contamination. In general, most of the sectors have a majority of medium risk areas, except for sectors 6 and 8 , in which this risk doesn't even represent $20 \%$ of the whole area. Sectors 3, 4, 6 and 10 can be considered the less susceptible to groundwater contamination due to the smaller percentage of high or medium to high-risk areas.

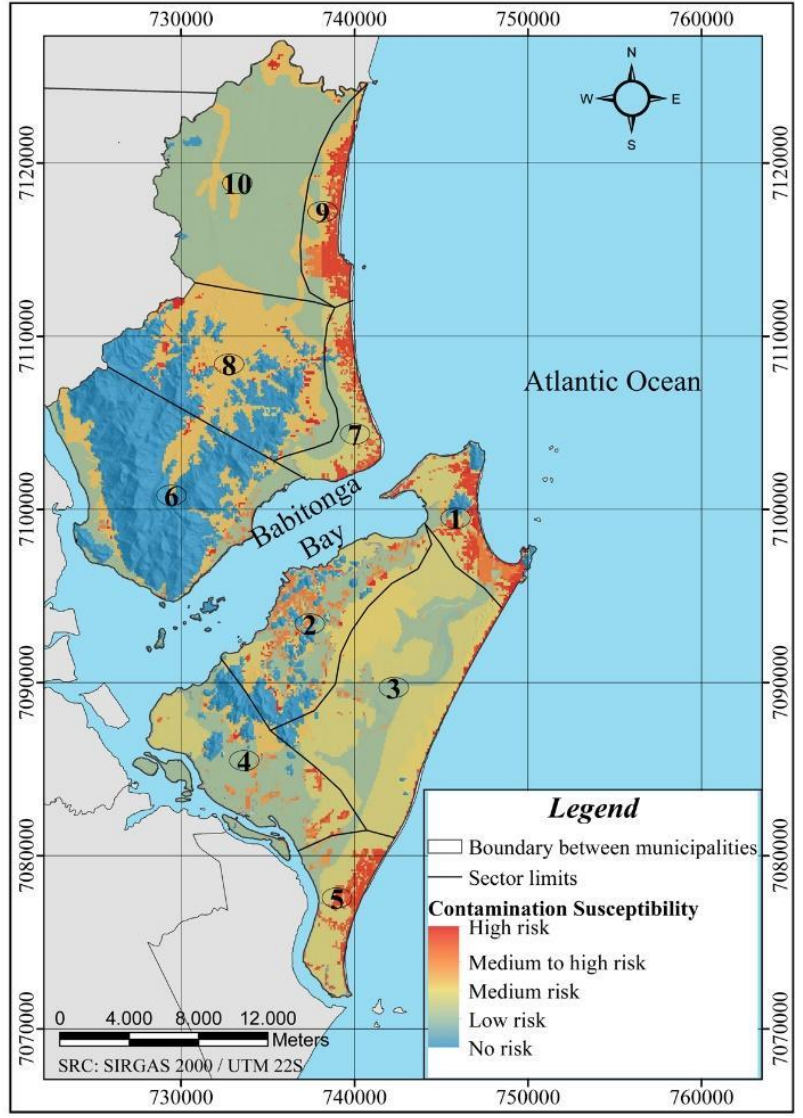

Figure 10. Map of groundwater susceptibility to contamination. High risk (2), Medium to high risk (1.7), Medium risk (1), Low risk (0.5), and No risk (0).

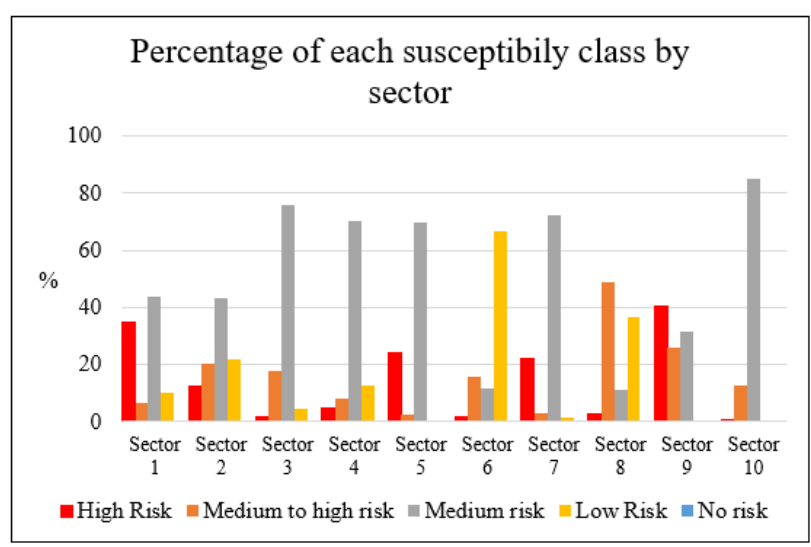

Figure 11. Graph showing the variation in area (\%) of each susceptibility class along the sectors in the São Francisco do Sul and Itapoá municipalities.

\section{DISCUSSION}

As the first objective of this research was to analyse the evolution of soil use and occupation in the São Francisco do Sul and Itapoá municipalities, focusing more specifically on variations in vegetation cover and on urban occupation, a major separation between 'vegetated area' and 'non-vegetated area' was prioritized. Despite this separation/segmentation can be totally performed by computer programs, GEOBIA requires the participation of the user and, in this sense, continuous attention is necessary during image interpretation, in order to generate an adequate separation of classes, according to the objectives and available tools. 
The initial identification of vegetated areas took into account the vegetation index (NDVI), which aided the separation of classes. Different types of vegetation - which were confirmed during field work - were observed, varying from the primary, native Atlantic Rainforest sandbank, and mangrove vegetations, to the secondary, reforesting species (mainly Eucalyptus) or grass. Nonetheless, this more detailed separation was not essential for the objective of the research, and therefore these vegetation types were grouped in the class 'vegetated area'. Planted areas were added to 'bare soil', because these are degraded areas by economic activity. They represented a challenge in the classification, because the images were acquired from different seasons and therefore the spectral responses concerning planting periods were merged with the 'vegetated area' class. As the crop's seasonality influences on the water saturation, this may alter the NDVI (Jensen, 2004) and it explains the differences on the threshold between vegetated and barren areas.

The 'non-vegetated areas' were divided in areas of bare soil and urban zones. The areas of bare soil are used for agriculture, sand mining, or are deforested areas only. It is worth reinforcing that deforestation has advanced with not only urbanization (residential and commercial real estate advance), but with areas made available for the storage of containers.

Zhang et al. (2002) states that the heterogeneity of urban areas and therefore the lack of spectral homogeneity, this presenting a difficulty to the precise identification of such regions. Also, Momeni el al. (2016) concluded that "spatial resolution is the most significant factor in determining the success or otherwise of mapping complex urban environments" and, as also pointed out by Toure et al. (2018), LANDSAT images have moderate spatial resolution, which limits the higher detailed classification of such complex's environments.

Table 3 and Figure 3 illustrate the changes in soil use and occupation in the São Francisco do Sul and Itapoá municipalities along 28 years. The inverse relationship between vegetated area and bare soil records a clear advance of deforestation from 1991 to 2000, and withdrawal in the following years. On the other hand, urban occupation has continuously grown along these years, with the acceleration of urban expansion approximately every decade. Extensive urbanization occurred in sectors 1, 2 and 5 of the São Francisco do Sul Island, with the development of a more rural zone in sector 4 . In sector 2 the advance of deforestation is related not only to urban advance, but also as support for infrastructure related to port operations (e.g., port terminals). Sector 3 includes most of the Acaraí Statal Park, which is an area of permanent protection, corroborating the restricted urban advance or deforestation in this sector. In the continental region opposite to the Babitonga Bay, advances of sectors 6, 7 and 9 are observed. The advance in sector 8 is related to agricultural development, as it concentrates most of the planted areas of the study area. Sector 10 presents only a few foci of urban development.

From 1991 to 2019, there has been the recovery of some regions classified as 'bare soil', thanks to reforesting measures taken by the municipalities. During field work, the introduction of new plant species was observed, attesting possible initiatives taken for the recovery of deforested areas. Table 3 shows that in 2019 the percentages of bare soil were the least since 1991. Despite the urbanized area has increased more than $3 \%$ in this period, there has been a decrease of non-vegetated areas, which can be explained by the reforesting measures mentioned before.
As almost the totality of the urban zone has developed in areas of high-risk unconsolidated sediment deposits, the susceptibility to groundwater contamination is higher than that considering only the fact that it is an urban region. The substrate is poorly resistant to infiltration, which increases the risk, especially in sectors 1, 5, 7, and 9 (figure 10). Despite the intense urbanization in sector 2, the presence headlands close to tidal plains has reduced the risk, even if susceptibility is medium to high. It should be mentioned that this is a preliminary spatial analysis of this region groundwater contamination susceptibility. Hence, further work is required to analyse the groundwater risk of contamination with well log data in order to assess with higher precision the actual rate of groundwater contamination in each sector.

It is worth mentioning that most of the State of Santa Catarina is devoid of sewerage systems, increasing the risk of pollution, as urban waste is not properly treated and disposed.

\section{CONCLUSIONS}

Based on the materials and methods applied in the present study, it was possible to quantitatively assess the evolution of soil use and occupation in the São Francisco do Sul and Itapoá municipalities between 1991 and 2019. It is worth mentioning object-oriented classification (GEOBIA) allowed to adequately separate different segments and classify them aiming at the identification of non-vegetated areas and zones of urban advance. Besides, as presented by Blaschke and Strobl (2001), Pinho, Feitosa and Kux (2005) and Blaschke et al. (2014) this method, when including the role of descriptors as determinant factors in classification, plus the interpretation of objects present in the image - and not the sole interpretation of isolated pixels -, potentializes the results and ensures an interpretation of the study area in a manner coherent with what is suggested in the literature.

As expected, the analysis of susceptibility to groundwater contamination showed that urban regions would represent the greatest risk. However, the results can aid measures to be taken so as to avoid future hazards to the environment and to the populations that depend on it.

In dealing with 30 meters pixel resolution, a lot of information concerning the objects may be lost, even the boundaries details between them. Even though more accurate and detailed analysis might have been achieved in using finer spatial resolution, the Kappa coefficient shows that a substantial accuracy was reached in this research. Nevertheless, further work with other spatial resolutions and accompanied by more detailed field work may improve even more the results and help assessing land use and land cover evolution through the years.

The main objective of the study was achieved, which was the analysis of soil use and occupation in the São Francisco do Sul and Itapoá municipalities, focusing on urban advance and risks to the environment. However, we believe in the possibility to explore the GEOBIA method in more detail using additional data, such as shallow and deep well log data, in order to better assess aquifer contamination.

\section{ACKNOWLEDGEMENT}

The authors wish to thank UFSC and the Data Processing and Georeferenced Information Laboratory for the support given to this research. 


\section{REFERENCES}

Blaschke, T., Strobl, J., 2001. What's wrong with pixels? Some recent developments interfacing remote sensing and GIS. GIS Zeitschrift für Geoinformationsysteme 14 (6), 12 - 17.

Blaschke, T., 2009. Object based image analysis for remote sensing. Isprs Journal of Photogrammetry and Remote Sensing. p. 2-16.

Blaschke, T., Hay, G.J., Kelly, M., Lang, S., Hofmann, P., Addink, E., Feitosa, R.Q., Meer, F.v.d., Werff, H.v.d., Coillie, F.v. Tiede, D., 2014. Geographic Object-based Image Analysis Towards a new paradigm. Isprs Journal of Photogrammetry and Remote Sensing. p. 180-191.

Foody, G.M. 1992., On the compensation for chance agreement in image classification accuracy assessment. Photogrametric Engineering and Remote Sensing, v. 58, n. 10, p. 1459-1460.

Horn Filho, N.O., 1997. O Quaternário costeiro da Ilha de São Francisco do Sul e arredores, Nordeste do Estado de Santa Catarina - aspectos geológicos, evolutivos e ambientais. 1997. 384 f. Thesis (Doctorate) - Geology Course, Institute of Geosciences, Federal University of Rio Grande do Sul.

Horn Filho, N. O.; Diehl, F. L., 2006. Santa Catarina Coastal Province, Brazil: Geology, Geomorphology and Paleogeography. Journal of Coastal Research. p. 311-315.

IBGE., 2004. Mapa de Biomas do Brasil. Scale 1:5.000.000. Environment Department.

Jensen, J.R., 2004. Introductory Digital Image Processing: A Remote Sensing Perspective. Upper Saddle River: Pearson Prentice Hall, Third Edition.

Kamann, P.J., Ritzi, R.W., Dominic, D.F., Conrad, C.M., 2007. Porosity and Permeability in Sediment Mixtures. Ground Water, v. 45, n. 4, p. 429-438. Wiley. doi.org/10.1111/j.17456584.2007.00313.x.

Kumar, P., Dasfupta, R., Johnson, B.A., Saraswat, C., Basu, M., Kefi, M., Mishra, B.K., 2019. Effect of Land Use Changes on Water Quality in an Ephemeral Coastal Plain: khambhat city, gujarat, india. Water, v. 11, n. 4, p. 724-739. MDPI AG. doi.org/10.3390/w11040724.

Landis, J.R., Koch, G.G., 1977. The measurement of observer agreement for categorical data. Biometrics 33, 159-174.

Meneses, P.R., Almeida, T., 2012. (Org.). Introdução ao Processamento de Imagens de Sensoriamento Remoto. Brasília: Cnpq, 266 p.

Momeni, R., Aplin, P., Boyd, D.S., 2016. Mapping Complex Urban Land Cover from Spaceborne Imagery: the influence of spatial resolution, spectral band set and classification approach. Remote Sensing, v. 8, n. 2, p. 88. MDPI AG. doi.org/10.3390/rs8020088.

Monserud, R.A., Leemans, R., 1992. Comparing global vegetation maps with the Kappa statistic. Ecol. Model. 62 (4), 275-293.

Morris, D. and Johnson, A., 1967. Summary of Hydrologic and Physical Properties of Rock and Soil Materials, as Analysed by the Hydrologic Laboratory of US Geological Survey 19481960, US Geological Survey, Washington, USA.
Pinho, C.M.D., Feitosa, F.F., Kux, H., 2005. Classificação automática de cobertura do solo urbano em imagem IKONOS: Comparação entre a abordagem pixel-a-pixel e orientada a objetos. In: Brazilian Symposium of Remote Sensing, Goiânia. Anais.... Goiânia: Inpe. p. 4217 - 4224.

Rubim, F.B., 2019. Avaliação da Vulnerabilidade Natural e Risco à Contaminação do Sistema Aquífero Campeche, Ilha de Santa Catarina - SC, Brasil. 83 f. TCC (Graduation) - Geology Course, Geology department, Federal University of Santa Catarina, Florianópolis.

Scanlon, B.R., Reedy, R.C., Stonestrom, D.A., Prudic, D.E., Dennehys, K.F., 2005. Impact of land use and land cover change on groundwater recharge and quality in the southwestern US. Global Change Biology, v. 11, n. 10, p. 1577-1593. Wiley. doi.org/10.1111/j.1365-2486.2005.01026.x.

Souza, M.C., 1999. Mapeamento da planície costeira e morfologia e dinâmica das praias do município de Itapoá, Santa Catarina: subsídios à ocupação. 169 f. Theses (Masters) Geology Course, Geology department, Federal University of Paraná, Curitiba.

Toure, S.I., Stow, D.A., Shih, H., Weeks, J., Lopez-Carr, D., 2018. Land cover and land use change analysis using multispatial resolution data and object-based image analysis. Remote Sensing of Environment, v. 210, p. 259-268. Elsevier BV. doi.org/10.1016/j.rse.2018.03.023.

Urumović, K.; SR., K.U., 2016. The referential grain size and effective porosity in the Kozeny-Carman model. Hydrology and Earth System Sciences, [S.L.], v. 20, n. 5, p. 1669-1680, Copernicus GmbH. doi.org/10.5194/hess-20-1669-2016.

Wang, X., 1989. The Relationship of Land Use and Groundwater Quality: A Case Study of Rhode Island. Open Access Master's Theses. Paper 660. https://digitalcommons.uri.edu/theses/660.

Wildner, W., Camozzato, E., Toniolo, J.A., Binoto, R.B., Iglesias, C.M.F., Laux, J.H., 2014. Mapa geológico do estado de Santa Catarina. Porto Alegre: CPRM. Scale 1:500.000. Geology program from Brazil. Regional Geological Cartography subprogram.

Zhang, Q., Yang, X., Zhang, Y., Zhong, M., 2013. Risk Assessment of Groundwater Contamination: a multilevel fuzzy comprehensive evaluation approach based on drastic model. The Scientific World Journal, v. 2013, p. 1-9, 2013. Hindwai Limited. doi.org/10.1155/2013/610390. 